Published in final edited form as:

J Clin Densitom. 2007 ; 10(4): 395-403.

\title{
Relationship of Circulating Total Homocysteine and C-Reactive Protein to Trabecular Bone in Postmenopausal Women
}

\author{
Shilpa N. Bhupathiraju ${ }^{1}$, D. Lee Alekel ${ }^{1}$, Jeanne W. Stewart ${ }^{1}$, Laura N. Hanson ${ }^{1}$, Kristine M. \\ Shedd $^{3}$, Manju B. Reddy ${ }^{1}$, Kathy B. Hanson ${ }^{1}$, Marta D. Van Loan ${ }^{3}$, Ulrike Genschel ${ }^{4}$, and \\ Kenneth J. Koehler ${ }^{4}$ \\ 1 Department of Food Science and Human Nutrition, Human Metabolic Unit, Center for Designing Foods to \\ Improve Nutrition, Iowa State University, Ames, Iowa
}

3 USDA ARS, WHNRC University of California, Davis, CA

4 Department of Statistics, Iowa State University, Ames, Iowa

\begin{abstract}
Homocysteine (Hcy) and C-reactive protein (CRP) are novel risk factors for osteoporosis. The purpose of this analysis was to determine the relationship of Hcy and CRP to volumetric trabecular bone, but also to assess their relationship to areal composite bone in healthy postmenopausal women $(\mathrm{N}=184)$. We used peripheral quantitative computed tomography to assess volumetric bone at the distal tibia and dual-energy x-ray absorptiometry to assess areal composite bone at the proximal femur and lumbar spine. Multiple regression revealed that $22 \%$ of the variability in trabecular bone mineral content $(\mathrm{F}=9.59, p \leq 0.0001)$ was accounted for by weight $(12.4 \% ; p \leq 0.0001)$, hemoglobin (5.5\%; $p=0.0006)$, uric acid $(4.2 \% ; p=0.003)$, and blood glucose $(1.5 \% ; p=0.07)$. Multiple regression revealed that $5.4 \%$ of the variability in trabecular bone mineral density $(\mathrm{F}=3.36 ; p=0.020)$ was accounted for by hemoglobin $(4.2 \% ; p=0.006)$ and Hcy $(1.5 \%$; not significant, $p=0.10)$. Total Hcy and CRP were not significantly related to trabecular bone, perhaps because these were nonosteoporotic women. However, our results suggested a weak but negative relationship between Hcy and trabecular bone. Further investigation is needed to examine the relationship of Hcy as an endogenous bioactive molecule to trabecular bone loss in early postmenopausal women and the response of trabecular bone to dietary intervention.
\end{abstract}

\section{Keywords}

homocysteine; C-reactive protein; pQCT; trabecular bone; osteoporosis; postmenopausal women

\section{INTRODUCTION}

\begin{abstract}
Osteoporosis and atherosclerotic cardiovascular disease (CVD) are major public health problems that often coexist and account for significant morbidity and mortality in postmenopausal women. The postmenopausal period typically occupies one-third of a woman's life, with more than 37.5 million women (aged 40-59 years) reaching menopause or currently menopausal (1). Homocysteine (Hcy) and C-reactive protein (CRP) are novel risk factors for osteoporosis. In particular, homocystinuria (a high concentration of urinary Hcy)
\end{abstract}

Correspondence to: D. Lee Alekel.

Publisher's Disclaimer: This is a PDF file of an unedited manuscript that has been accepted for publication. As a service to our customers we are providing this early version of the manuscript. The manuscript will undergo copyediting, typesetting, and review of the resulting proof before it is published in its final citable form. Please note that during the production process errors may be discovered which could affect the content, and all legal disclaimers that apply to the journal pertain. 
constitutes a markedly increased risk for osteoporosis, suggesting that a high serum Hcy concentration may weaken bone (2-5). Typically, Hcy increases with age (6) and is higher in postmenopausal than premenopausal women (7). Polymorphisms in enzymes involved in the Hcy metabolic pathway also increase fracture risk (8) and affect biochemical markers of bone turnover (9). As an acute phase proinflammatory protein, CRP is widely used as a screening tool for CVD risk and confers additional prognostic value in those with and without subclinical atherosclerosis (10). Inflammation contributes to both atherosclerosis and osteoporosis, thus providing the biological plausibility for the potential use of CRP as a marker of both atherosclerotic and osteoporotic risk.

To our knowledge, no studies have been published to examine the relationship of total Hcy and CRP with trabecular bone. This is of primary importance, as trabecular bone reflects metabolically active bone, which is preferentially lost during menopause and thus is of interest in assessing early osteoporotic risk (11). Peripheral quantitative computed tomography (pQCT) offers a novel, noninvasive (12), accurate (13), and precise (14) method to assess volumetric bone mineral density (BMD), bone size, cortical geometry (15), and apparent trabecular structure and connectivity (11). In addition, pQCT determines volumetric (three dimensional) BMD, providing an assessment of trabecular bone, whereas dual energy x-ray absorptiometry (DXA) determines areal (two dimensional) BMD, providing an assessment of composite bone. The purpose of this analysis was to investigate the relationship of Hcy and CRP particularly to trabecular bone using pQCT, but also to composite bone, using DXA in a sample of healthy postmenopausal women. We hypothesized that trabecular bone would be more sensitive than composite bone to endogenous bioactive molecules, such as Hcy and CRP. Thus, we anticipated that Hcy and CRP would not be related to composite bone, but would be inversely associated with trabecular bone as assessed by pQCT.

\section{MATERIALS AND METHODS}

\section{Research Design}

We enrolled healthy postmenopausal women (45.8-65.0 years of age) as part of a randomized, double-blind, placebo-controlled multi-center (Iowa State University [ISU], Ames, IA and University of California at Davis [UC-Davis], Davis, CA) NIH-funded (\#RO1 AR046922 A2) clinical trial. This parent study (Soy Isoflavones for Reducing Bone Loss; SIRBL) is designed to examine the effect of two doses of isoflavones extracted from soybeans on bone loss during the course of three years in at-risk early postmenopausal (e.g., less than 10 years since their last menses) women. Eligible participants (non-osteoporotic, without diseases or conditions, not taking hormones or medications) were enrolled in the parent project. This report examines their baseline data as part of an ancillary project to determine the relationship between total Hcy and CRP and trabecular bone using pQCT.

\section{Subject Screening, Selection, and Characteristics}

We recruited subjects throughout the state of Iowa and the Sacramento region in California primarily through direct mailing lists, stories in local newspapers, local/regional radio advertisements, as well as other recruiting avenues. We screened women who responded $(\mathrm{N}=5,255)$ to outreach materials initially via a telephone questionnaire to identify healthy women who went through a natural menopause (cessation of menses nine months to ten years), were $\leq 65$ years of age, non smokers, and had a body mass index (BMI, $\mathrm{kg} / \mathrm{m}^{2}$ ) ranging from 18.5 through 29.9 (inclusive). We excluded women with currently diagnosed or previous history of bone disease, renal disease, urinary stones, cancer, malignancy or tumor of any kind, CVD, diabetes mellitus, respiratory disease, parathyroid disease, thyroid or liver disease, and/ or those women who had a first-degree relative with breast cancer. Additionally, we also excluded women who chronically used medications, such as cholesterol-lowering or anti- 
hypertensive medications. Use of oral hormone or estrogen therapy, selective estrogen receptor modulators, or other hormones within the last 12 months, use of estrogen or progestogen creams or calcitonin within the last six months, use of antibiotics within the last three months, and/or any previous use of bisphosphonates were grounds for exclusion. We also excluded vegans and high alcohol consumers ( $>7$ servings per week). We also excluded potential subjects with excessive vasomotor symptoms from the study.

Women who met the initial criteria via telephone $(\mathrm{N}=677)$ attended a pre-baseline appointment to determine eligibility for additional entry criteria. We measured height and weight to confirm BMI status. To determine eligibility, we used DXA to assess BMD of the lumbar spine and left proximal femur. Women with evidence of osteopenia or osteoporosis based on lumbar spine and/or proximal femur BMD (using >1.5 SD below the young adult mean as cutoff) and women with evidence of previous or existing spinal fractures were excluded. We also excluded women with spine and/or femur BMD >1.0 SD above the mean. If a woman qualified based on her BMD, our phlebotomist drew blood for a chemistry profile. We excluded women if their fasted blood values indicated diabetes mellitus (fasting blood glucose $\geq 126 \mathrm{mg} / \mathrm{dl}$ ), abnormal renal, liver, and/or thyroid function, or abnormal lipid profile (low density lipoproteincholesterol >160 mg/dl; triacylglycerol >200 mg/dl). For this ancillary project using pQCT, we examined 184 of the 242 women who met our entry criteria (Figure 1).

The study protocol, consent form, and subject-related materials were approved by the respective Institutional Review Boards (IRB) at ISU (ID\# 02-199) and at UC-Davis (ID\# 200210884-2). Approvals for the DXA and pQCT procedures were obtained from each institution's IRB and appropriate safety boards. We obtained informed consent from all women at the start of pre-baseline screening.

\section{Data Collection}

At the pre-baseline visit to ensure the health status of participants, trained interviewers administered three questionnaires: health and medical history, reproductive history, and nutrition history. Estrogen exposure (in years) was calculated for each subject by subtracting her age at menarche from her age at her last menstrual cycle. At the baseline testing appointment, we assessed dietary intake using a semi-quantitative food frequency questionnaire from Block Dietary Data Systems (Berkeley, CA). A trained anthropometrist at each geographic site measured standing and sitting heights (Ayrton stadiometer, Model S100; Ayrton Corp., Prior Lake, MN); weight (abco Health-o-meter; Health-o-meter Inc., Bridgeview, IL); waist, hip, and abdominal circumferences. Subjects were asked to cease taking herbal therapies and/or nutritional/dietary supplements prior to baseline testing. Phlebotomists collected fasted ( 9 hours) blood samples between 7:00 and 8:00 a.m. We separated serum and plasma from whole blood by centrifuging for 15 minutes $\left(4^{\circ} \mathrm{C}\right)$ at 1000 $\times \mathrm{g}$ and stored aliquots at $-80^{\circ} \mathrm{C}$ until analyses.

\section{Bone Measurements}

The bone measurement procedures were approved by the State Department of Public Health in both Iowa and California. Matching instruments at each site and daily calibration ensured that the pQCT and DXA instruments provided comparable results. One operator at ISU and one at UC-Davis performed all pQCT and DXA scans, with cross-training for pQCT and DXA scanning between sites to ensure comparable quality control. One research assistant at UCDavis performed pQCT scan analyses for both clinical sites following guidelines provided by Bone Diagnostic, Inc. (Fort Atkinson, WI). One research scientist at ISU performed DXA scan analyses for both clinical sites following Hologic (Bedford, MA) guidelines for bone mineral content (BMC) using software version 12.3:7. We assessed trabecular BMC and BMD at the distal tibia using pQCT (XCT 3000; STRATEC Medizintechnik, Pforzheim, Germany, 
Division of Orthometrix; White Plains, NY). A scout view was conducted to locate the distal end of the tibia, with the computer programmed to subsequently determine the $4 \%$ site proximal to the distal end. Because of improper alignment at the $4 \%$ distal tibia site and equipment failure at UC-Davis, we have used a subset of subjects $(\mathrm{N}=184)$ for the current analyses. The withinsubject in vivo precision error (coefficient of variation; $\mathrm{CV}$ ) for trabecular BMD at the distal tibia at ISU $(\mathrm{n}=10)$ and UC-Davis $(\mathrm{n}=8)$ using pQCT was $1.2 \%$ and $0.3 \%$, respectively. Total proximal femur and lumbar spine (L1-L4) BMC and BMD were assessed via a Delphi W DXA instrument. The within-subject in vivo CV for areal BMD at ISU using DXA was $1.1 \%$ at the spine and $0.7 \%$ at the hip. The within-subject in vivo CV for areal BMD at UC-Davis using DXA was $0.9 \%$ at the spine and $0.8 \%$ at the hip.

\section{Laboratory Measurements}

Blood samples were analyzed by certified clinical laboratories (LabCorp; Kansas City, Kansas at the ISU site and the UC-Davis Medical Center Laboratory; Sacramento, CA at UC-Davis site) for a complete blood count (CBC) with differential, general chemistry panel, and thyroid screen (thyroid stimulating hormone (TSH) with reflex to free thyroxine $\left(\mathrm{T}_{4}\right)$ if TSH was abnormal). For hemoglobin, the number of subjects included is 180 , since four CBCs were missing.

Total Hcy concentration was determined using a high performance liquid chromatography (HPLC) method adapted from Araki and Sako (16) and Ubbink et al. (17). The total Hcy in plasma consists of free Hcy (i.e., reduced plus oxidized Hcy in the non-protein fraction of plasma) and protein-bound Hcy (16). N-Acetylcysteine (1 mM) was added as an internal standard to the plasma samples prior to derivatization. All derivatized samples were filtered (ISO-DISC PTFE-4-2, $4 \mathrm{~mm} \times 0.2 \mu \mathrm{m}$; SUPLECO, Bellefonte, PA) into vials and frozen at $-20^{\circ} \mathrm{C}$ until analyzed. Derivatized samples were analyzed by HPLC (Beckman Coulter System Gold 126 Solvent Module and Beckman Gold 508 Autosampler; Fullerton, CA) using a reverse phase LC-18 column (SUPELCOSIL ${ }^{\mathrm{TM}} ; 25 \mathrm{~cm} \times 4.6 \mathrm{~mm}, 5 \mu \mathrm{m}$; SUPLECO, Bellefonte, PA), protected by an LC-18 guard column (SUPELCOSIL ${ }^{\mathrm{TM}}$ LC-18 Supelguard ${ }^{\circledR}$ Cartridge; SUPLECO, Bellefonte, PA). The fluorescence intensities were measured with excitation at $385 \mathrm{~nm}$ and emission at $515 \mathrm{~nm}$, using a JASCO FP-1520 fluorescence detector. The intraassay and inter-assay CVs were $3.8 \%$ and $6.3 \%$, respectively.

CRP concentration was determined in serum using a high sensitivity sandwich enzyme-linked immunosorbent assay kit (ALPCO Diagnostics; Salem, NH). Intracellular folate, serum folate, and serum vitamin $B_{12}$ were measured using a radioactive immunoassay kit (MP Biomedicals; Irvine, CA). Because four hematocrit values were missing, intracellular folate could not be calculated for these four samples. In addition, three baseline samples were incorrectly processed; thus, values presented for intracellular folate included 177 women. We used manufacturer-provided and in-house quality controls for calculating intra- and inter-assay CVs. The intra-assay $\mathrm{CV}$ for CRP, intracellular folate, serum folate, and serum vitamin $\mathrm{B}_{12}$ was $3.5 \%, 3.2 \%, 3.3 \%$, and $2.0 \%$, respectively. The inter-assay CV for CRP, intracellular folate, serum folate, and serum vitamin $\mathrm{B}_{12}$ was $6.0 \%, 11.8 \%, 10.8 \%$ and $5.5 \%$, respectively.

\section{Statistical Analyses}

For the parent project, women are currently participating in serial testing through three years of treatment. However, in this ancillary project, we are reporting only baseline data for 184 women. Power analysis for the parent study is based on a random effects repeated measures (18) regression model of change in lumbar spine BMD via DXA as the outcome variable. Statistical analyses were performed using SAS (version 9.1; Cary, NC) with results considered statistically significant at $p \leq 0.05$. Descriptive statistics included means for normally distributed data (age, years since menopause, estrogen exposure, body size, body composition, and bone 
data) and medians for data that were not normally distributed (total Hcy, serum CRP, and dietary intake). We excluded subjects $(\mathrm{n}=6)$ with CRP values $>10 \mathrm{mg} / \mathrm{L}$ from all inferential statistics, based on recommendations from the Centers for Disease Control \& Prevention and the American Heart Association (19). To examine relationships between total Hcy and CRP versus various measures of bone, we used Spearman's rho correlation analyses. In modeling the outcomes of interest, we removed variables that exhibited multicollinearity as indicated by the variance inflation factor. Variance inflation factor measures the impact of collinearity among the independent variables in a regression equation and the degree to which multicollinearity degrades the precision estimate. Typically, a value exceeding 10 is of concern, but in weaker regression models, a value exceeding 2.5 may be cause for concern (20). We performed multiple regression analyses to assess the combined contribution of factors (weight, age, blood glucose, hemoglobin, serum uric acid, plasma total Hcy, serum CRP, and total calcium [dietary plus supplemental] intake) related to trabecular BMC and BMD via pQCT. Classes of variables in modeling the outcomes of baseline trabecular BMC and BMD included all covariates that were biologically plausible and/or significantly related to bone in the Spearman's rho correlation analysis. In all regression models, study site was included as an obligatory variable to account for potential site differences.

\section{RESULTS}

\section{Subject Characteristics}

The baseline characteristics of women are described in Table 1. At baseline, women ranged from 46.1 to 65.0 years of age and from 0.9 to 10.2 years since menopause. The majority of women were Caucasian, although ISU enrolled one African American and one woman of more than one race, and UC-Davis enrolled one Native Hawaiian, one Asian, five women of more than one race, and two of unknown race. The vast majority of the subjects reported that they were not vegetarians, with only three vegetarians (two pesco, one lacto-ovo). More than half of the subjects reported a family history of CVD, about one fourth reported a family history of osteoporosis while more than one third reported a personal history of bone fracture. The most common form of past hormone therapy use was combined estrogen plus progestogen therapy, with a wide range of duration in general for any formula. Any use of estrogen or hormone therapy was discontinued at least one year prior to enrollment in the study.

Women had a wide range (18.4 - 31.3) of BMI values; approximately half had a BMI $<25.0$ $\mathrm{kg} / \mathrm{m}^{2}$. Areal bone measurements assessed via DXA and volumetric bone measurements (distal tibia reflecting trabecular bone) assessed via pQCT are presented in Table 2. All bone measures were normally distributed and thus mean values are reported. We report median values of circulating analytes as they were not normally distributed (Table 3). Approximately $45 \%$ of the subjects had normal CRP $(<1 \mathrm{mg} / \mathrm{L}), 40 \%$ had moderately elevated CRP $(1-3 \mathrm{mg} / \mathrm{L})$, and $15 \%$ had high CRP ( $>3 \mathrm{mg} / \mathrm{L})$ values. Recall that we excluded subjects $(\mathrm{n}=6 ; 3 \%$ of sample) with CRP values $>10 \mathrm{mg} / \mathrm{L}$ from all inferential statistics. We have included the intracellular folate concentration for 177 women in the descriptive statistics (Table 3) because four women were missing $\mathrm{CBC}$ and thus hematocrit values and three samples were incorrectly processed. Based on the clinical cut-off of $100 \mathrm{mg} / \mathrm{dL}$ (21), about $6 \%$ of women had impaired fasting glucose $(>100 \mathrm{mg} / \mathrm{dL})$. The median dietary intake for riboflavin, vitamin $\mathrm{B}_{6}$, and vitamin $\mathrm{B}_{12}$ approximated the dietary reference intakes (DRIs) for each of these nutrients. However, this was not the case for folic acid. The median total calcium (dietary plus supplemental) intake at baseline was $1204 \mathrm{mg}$ daily (Table 4), meeting the DRI for calcium (1200 mg/day). At both sites combined, lifetime calcium intake from dairy products decreased consistently from childhood, when milk intake was the highest, to mature adulthood, with this decline being particularly pronounced for the UC-Davis women. In general, women at ISU tended to have 
higher lifetime calcium intakes compared to their UC-Davis counterparts. The percentage of women who took calcium supplements was $71 \%$ at ISU and $65 \%$ at UC-Davis.

\section{Correlation Analyses}

Spearman's rho correlation analysis indicated a positive correlation between CRP and trabecular BMD of the distal tibia $(\mathrm{r}=0.178, p=0.017)$ assessed via $\mathrm{pQCT}$. Although our women did not report any chronic diseases at baseline, approximately half of the women $(n=92)$ had $\mathrm{CRP}$ values $\geq 1.0 \mathrm{mg} / \mathrm{L}$. Thus, examining a subsample of women with elevated CRP $(>1.8 \mathrm{mg} /$ $\mathrm{L}, \mathrm{n}=49$ ) based on the cut-off value from Koh et al. (22), we did not detect a significant correlation between CRP and bone. Further, we found no statistically significant association between total Hcy, intracellular or serum folate, or serum vitamin $\mathrm{B}_{12}$ and trabecular bone measurements in these healthy postmenopausal women.

\section{Regression Analyses}

We performed analyses to examine factors contributing to the variability in trabecular bone as our primary outcome of interest. Factors contributing to the variability of trabecular BMC and BMD are presented in Table 5. We initially included the following variables in the models: age, weight, blood glucose, hemoglobin, serum uric acid, serum CRP, total Hcy, and total calcium intake (dietary plus supplemental from Food Frequency Questionnaire). After variable elimination was completed, multiple regression analyses revealed that $22 \%$ of the variability in trabecular BMC ( $\mathrm{F}=9.59, p \leq 0.0001)$ was accounted for by hemoglobin, uric acid, weight, and fasting blood glucose. Serum uric acid $(p=0.0027)$ contributed negatively to trabecular BMC. In contrast, baseline body weight $(p \leq 0.0001)$ and hemoglobin $(p=0.0006)$ contributed positively to trabecular BMC. Variables that remained in the model (except site) were significant at $p<0.10$. Although geographic site did not reach significance, we kept site in both models to account for potential site differences. After variable elimination was completed, multiple regression analyses revealed that $5.4 \%$ of the variability in trabecular $\mathrm{BMD}(\mathrm{F}=3.36$; $p=0.020)$ was accounted for by hemoglobin $(4.2 \% ; p=0.006)$ and Hcy $(1.5 \%$; not significant, $p=0.102)$.

\section{DISCUSSION}

Menopause contributes to significant risk for postmenopausal women in developing osteoporosis (23) and atherosclerotic CVD (24). Many risk factors including elevated Hcy (7) and CRP are more likely to emerge after rather than prior to menopause. To our knowledge, this is the only study examining the relationship between total Hcy and CRP versus trabecular bone assessed via $\mathrm{pQCT}$ in healthy postmenopausal women. A few studies have related high total Hcy to low BMD (2-4). However, no studies have examined the relationship between total Hcy and trabecular bone.

Contrary to previous findings $(2-4,25)$, we did not demonstrate a relationship between circulating total Hcy and areal bone via DXA. Although we hypothesized that total Hcy would be inversely associated with trabecular bone, correlation analysis did not reveal a significant association between total Hcy and trabecular BMC $(\mathrm{r}=-0.041, p=0.58)$ or BMD $(\mathrm{r}=-0.060$, $p=0.42$ ). Nonetheless, once other factors were taken into account in the regression model, the presence of an inverse relationship (albeit not significant) suggested the potential role of Hcy in osteoporotic risk. The vast majority of women in our study had normal total Hcy, whereas previous epidemiological studies have demonstrated an increased risk of osteoporotic fracture only in subjects with high Hcy ( $>15 \mu \mathrm{mol} / \mathrm{L})$. For example, in the Hordaland Homocysteine Study (3), the multiple adjusted odds ratio for low BMD was 1.96 in those with high $(\geq 15$ $\mu \mathrm{mol} / \mathrm{L})$ compared with low $(<9 \mu \mathrm{mol} / \mathrm{L}) \mathrm{Hcy}$. Similarly, the Framingham Study (4) showed that subjects in the highest quartile $(18.6 \pm 6.4 \mu \mathrm{mol} / \mathrm{L})$ had a greater risk of hip fracture than 
those in the lowest quartile $(7.6 \pm 1.0 \mu \mathrm{mol} / \mathrm{L})$ of total Hcy. Gerdhem et al. (2) reported a decrease in femoral neck BMD in elderly women in the highest Hcy quartile (17.4-109.0 $\mu \mathrm{mol} / \mathrm{L})$ compared to those in the lower three quartiles $(6.2-17.3 \mu \mathrm{mol} / \mathrm{L})$. However, this relationship was not observed for lumbar spine BMD. Plasma total Hcy concentration was slightly higher $(7.7 \pm 2.2 \mu \mathrm{mol} / \mathrm{L})$ in our subjects than that recently reported for women $(6.8 \pm$ $0.1 \mu \mathrm{mol} / \mathrm{L}$ ) from the 2001-2002 NHANES data (6), but was comparable to the lowest quartile of total Hcy for women $(7.6 \pm 1.0 \mu \mathrm{mol} / \mathrm{L})$ in the Framingham Study (3). Only four women in our study had high $(\geq 15 \mu \mathrm{mol} / \mathrm{L})$ plasma total Hcy, possibly explaining why we did not detect a relationship between Hcy and bone in these healthy postmenopausal women.

Nonetheless, we identified not only known but also less recognized factors that contributed to the variability in trabecular bone. Hemoglobin emerged as a significant contributor to trabecular bone. This may be because trabecular bone is highly vascularized, well innervated, and responsible for hematopoiesis and mineral homeostasis. Subjects with a higher hemoglobin concentration may have better oxygen delivery to all tissues, including bone, thereby increasing trabecular bone. It is important to note that hemoglobin is fairly stable in postmenopausal women who no longer have monthly blood losses. Reporting similar results, Cesari et al. (26) concluded that hemoglobin was significantly (positive direction) associated with total (at the calf; $p=0.03)$, as well as both trabecular $(p=0.02)$ and cortical $(p=0.03)$ bone density, using pQCT in older women. One may speculate that a low hemoglobin concentration due to iron deficiency anemia may impact bone by reducing trabecular bone density. To illustrate, the lumbar vertebrae of female rats either on an iron restricted $(12 \mathrm{mg} \mathrm{Fe} / \mathrm{kg} /$ day $)$ but calcium adequate $(5.2 \mathrm{~g} \mathrm{Ca} / \mathrm{kg} \mathrm{diet})$ diet (27) or an iron deficient diet ( $<8 \mathrm{mg} \mathrm{Fe} / \mathrm{kg} /$ day; [28]) had a lower trabecular number and greater trabecular separation using micro-computed tomography. The activity of prolyl hydroxylase, essential to hydroxyproline cross-linking in bone, is irondependent (29), providing a possible explanation for the role of iron in collagen and hence bone. Perhaps this is one explanation as to why we noted the consistent association of hemoglobin with trabecular bone in these women, suggesting that preventing anemia may be important for reducing risk of osteoporosis. Although serum ferritin is a better indicator of iron status than hemoglobin, surprisingly, we did not find any relationship between serum ferritin and trabecular bone (data not shown) in this sample of healthy postmenopausal women.

Although women in our study had normal kidney function, we observed a negative association between circulating uric acid and trabecular BMC, perhaps illustrating the relationship of kidney function to bone. Pietschmann et al. (30) reported that patients with absorptive hypercalciuria and lower vertebral BMD exhibited a trend toward increased uric acid excretion. In our study, we did not measure urinary uric acid, but rather serum uric acid. The relationship between serum uric acid and BMD should be further investigated. Additionally, weight contributed to trabecular BMC, similar to what has been reported in previous studies (31).

A few studies have demonstrated an association between CRP concentration and BMD or biochemical markers of bone turnover in immune (32) and inflammatory $(33,34)$ disease states. However, there is a paucity of data examining this relation in healthy postmenopausal subjects without inflammatory conditions, similar to our subjects. Our median CRP value was less than what was reported by Bassuk et al. (10) for American women not on hormone therapy. Contrary to our hypothesis, CRP was not associated with distal tibia trabecular BMC or BMD either with correlation or multiple regression analyses.

The median CRP concentration $(1.1 \mathrm{mg} / \mathrm{L})$ in our study was similar to that reported by Koh et al. (22) in Korean women $(1.0 \mathrm{mg} / \mathrm{L})$, but was slightly lower than the concentration $(1.5 \mathrm{mg} /$ L) in apparently healthy American women (35). Our results indicating no correlation between CRP and trabecular bone do not agree with Koh et al. (22), who demonstrated that higher circulating CRP was associated with lower femoral neck BMD in postmenopausal Korean 
women. However, women from their study were late postmenopausal ( $7.7 \pm 5.7$ years) compared to our women $(3.5 \pm 2.0$ years since menopause $)$ and we focused on trabecular bone. More importantly, osteopenic and osteoporotic women in their study had a significantly greater $(p \leq 0.014) \mathrm{CRP}$ concentration compared with healthy postmenopausal women. Since we excluded women with a BMD T-score below -1.5, it is possible that we were unable to detect a relationship between CRP and bone because our women were more uniform with respect to BMD. To further explore this relationship, we examined women with CRP values above and below $1.8 \mathrm{mg} / \mathrm{L}$, based on the association of CRP above this value with osteopenia and/or osteoporosis as noted in the Korean study (22). In our women with elevated CRP, we found no association between CRP and any trabecular bone measurement. Contrary to results from Koh et al. (22), high CRP (>1.8 mg/L) did not appear to confer elevated risk of osteoporosis in this group of healthy postmenopausal women.

In conclusion, total Hcy and CRP were not significantly related to trabecular bone in our healthy, non-osteoporotic postmenopausal women. Yet, once various factors were taken into account, our regression results suggested a weak (albeit not significant) but negative relationship between Hcy and trabecular bone. However, the majority of our participants had normal Hcy and CRP concentrations, with only a few moderately elevated values, suggesting that low or normal values do not impact trabecular bone in healthy postmenopausal women.

We acknowledge that peripheral measurements of trabecular bone using pQCT do not perfectly reflect the axial skeleton, but this technology is nevertheless quite useful. Further investigation is needed to examine the relationship of hyperhomocysteinemia and elevated CRP to trabecular bone loss in early postmenopausal women and the response of trabecular bone to dietary intervention.

\section{References}

1. Centers for Disease Control \& Prevention. [Accessed May 24th 2007]. http://www.cdc.gov/ reproductivehealth/WomensRH/Menopause.htm

2. Gerdhem P, Ivaska KK, Isaksson A, et al. Associations between homocysteine, bone turnover, BMD, mortality, and fracture risk in elderly women. J Bone Miner Res 2007;22:127-134. [PubMed: 17032146]

3. Gjesdal CG, Vollset SE, Ueland PM, et al. Plasma total homocysteine level and bone mineral density: the Hordaland Homocysteine Study. Arch Intern Med 2006;166:88-94. [PubMed: 16401815]

4. McLean RR, Jacques PF, Selhub J, et al. Homocysteine as a predictive factor for hip fracture in older persons. N Engl J Med 2004;350:2042-2049. [PubMed: 15141042]

5. van Meurs JB, Dhonukshe-Rutten RA, Pluijm SM, et al. Homocysteine levels and the risk of osteoporotic fracture. N Engl J Med 2004;350:2033-2041. [PubMed: 15141041]

6. Ganji V, Kafai MR. Trends in serum folate, RBC folate, and circulating total homocysteine concentrations in the United States: analysis of data from National Health and Nutrition Examination Surveys, 1988-1994, 1999-2000, and 2001-2002. J Nutr 2006;136:153-158. [PubMed: 16365075]

7. Hak AE, Polderman KH, Westendorp IC, et al. Increased plasma homocysteine after menopause. Atherosclerosis 2000;149:163-168. [PubMed: 10704628]

8. Hong X, Hsu YH, Terwedow H, et al. Association of the methylenetetrahydrofolate reductase C677T polymorphism and fracture risk in Chinese postmenopausal women. Bone 2007;40:737-742. [PubMed: 17174622]

9. Kim DJ, Park BL, Koh JM, et al. Methionine synthase reductase polymorphisms are associated with serum osteocalcin levels in postmenopausal women. Exp Mol Med 2006;38:519-524. [PubMed: 17079868]

10. Bassuk SS, Rifai N, Ridker PM. High-sensitivity C-reactive protein: clinical importance. Curr Probl Cardiol 2004;29(8):439-493. [PubMed: 15258556] 
11. Takagi Y, Fujii Y, Miyauchi A, Goto B, Takahashi K, Fujita T. Transmenopausal change of trabecular bone density and structural pattern assessed by peripheral quantitative computed tomography in Japanese women. J Bone Miner Res 1995;10:1830-1840. [PubMed: 8592962]

12. Grampp S, Lang P, Jergas M, et al. Assessment of the skeletal status by peripheral quantitative computed tomography of the forearm: Short-term precision in vivo and comparison to DXA. J Bone Miner Res 1995;10:1566-1576. [PubMed: 8686514]

13. Ebbesen EN, Thomsen JS, Mosekilde L. Nondestructive determination of iliac crest cancellous bone strength by pQCT. Bone 1997;21:535-540. [PubMed: 9430244]

14. Sievanen H, Koskue V, Rauhio A, Kannus P, Heinonen A, Vuori I. Peripheral quantitative computed tomography in human long bones: Evaluation of in vitro and in vivo precision. J Bone Miner Res 1998;13:871-882. [PubMed: 9610752]

15. Rauch F, Klein K, Allolio B, Schonau E. Age at menarche and cortical bone geometry in premenopausal women. Bone 1999;25:69-73. [PubMed: 10423024]

16. Araki A, Sako Y. Determination of free and total homocysteine in human plasma by high-performance liquid chromoatography with fluorescence detection. J Chromatogr 1987;422:43-52. [PubMed: 3437026]

17. Ubbink JB, Vermaak WJH, Bissbort S. Rapid high-performance liquid chromatographic assay for total homocysteine levels in human serum. J Chromatogr 1991;565:441-446. [PubMed: 1874890]

18. Laird NM, Ware JH. Random-effects models for longitudinal data. Biometrics 1982;38:963-974. [PubMed: 7168798]

19. Pearson TA, Mensah GA, Alexander RW, et al. Centers for Disease Control and Prevention; American Heart Association. Markers of inflammation and cardiovascular disease: application to clinical and public health practice: A statement for healthcare professionals from the Centers for Disease Control and Prevention and the American Heart Association. Circulation 2003;107:499-511. [PubMed: 12551878]

20. Allison, PD. Logistic regression using the SAS system: Theory and application. SAS Institute Inc; Cary, NC: 1999.

21. The Expert Committee on the Diagnosis and Classification of Diabetes Mellitus. Follow-up report on the diagnosis of diabetes mellitus. Diabetes Care 2003;26:3160-3167. [PubMed: 14578255]

22. Koh JM, Khang YH, Jung CH, et al. Higher circulating hsCRP levels are associated with lower bone mineral density in healthy pre- and postmenopausal women: evidence for a link between systemic inflammation and osteoporosis. Osteoporos Int 2005;16:1263-1271. [PubMed: 15702263]

23. Scheiber MD, Rebar RW. Isoflavones and postmenopausal bone health: a viable alternative to estrogen therapy? Menopause 1999;6:233-241. [PubMed: 10486794]

24. Welty FK. Women and cardiovascular risk. Am J Cardiol 2001;88:48J-52J.

25. Baines M, Kredan MB, Usher J, et al. The association of homocysteine and its determinants MTHFR genotype, folate, vitamin B12 and vitamin B6 with bone mineral density in postmenopausal British women. Bone 2007;40:730-736. [PubMed: 17141597]

26. Cesari M, Pahor M, Lauretani F, et al. Bone density and hemoglobin levels in older persons: results from the InCHIANTI study. Osteoporos Int 2005;16:691-699. [PubMed: 15455197]

27. Parelman M, Stoecker B, Baker A, Medeiros D. Iron restriction negatively affects bone in female rats and mineralization of hFOB osteoblast cells. Exp Biol Med (Maywood) 2006;231:378-386. [PubMed: 16565433]

28. Medeiros DM, Stoecker B, Plattner A, Jennings D, Haub M. Iron deficiency negatively affects vertebrae and femurs of rats independently of energy intake and body weight. J Nutr 2004;134:30613067. [PubMed: 15514276]

29. Tuderman L, Myllyla R, Kivirikko KI. Mechanism of the prolyl hydroxylase reaction. 1. Role of cosubstrates. Eur J Biochem 1977;80:341-348. [PubMed: 200424]

30. Pietschmann F, Breslau NA, Pak CY. Reduced vertebral bone density in hypercalciuric nephrolithiasis. J Bone Miner Res 1992;7:1383-1388. [PubMed: 1481724]

31. Guglielmi G, van Kuijk C, Li J, Meta MD, Scillitani A, Lang TF. Influence of anthropometric parameters and bone size on bone mineral density using volumetric quantitative computed tomography and dual X-ray absorptiometry at the hip. Acta Radiol 2006;47:574-580. [PubMed: 16875335] 
32. Bakri Hassan A, Ronnelid J, Gunnarsson I, Karlsson G, Berg L, Lundberg I. Increased serum levels of immunoglobulins, C-reactive protein, type 1 and type 2 cytokines in patients with mixed connective tissue disease. J Autoimmun 1998;11:503-508. [PubMed: 9802936]

33. Haugeberg G, Green MJ, Quinn MA, et al. Hand bone loss in early undifferentiated arthritis. Evaluating BMD loss before the development of rheumatoid arthritis. Ann Rheum Dis 2006;65:736740. [PubMed: 16284095]

34. Punzi L, Ramonda R, Oliviero F, et al. Value of $\mathrm{C}$ reactive protein in the assessment of erosive osteoarthritis of the hand. Ann Rheum Dis 2005;64:955-957. [PubMed: 15897314]

35. Rifai N, Ridker PM. Population distributions of C-reactive protein in apparently healthy men and women in the United States: implication for clinical interpretation. Clin Chem 2003;49:666-669. [PubMed: 12651826]

36. Ganji V, Kafai MR. Third National Health Nutrition Examination Survey. Demographic, health, lifestyle, and blood vitamin determinants of serum total homocysteine concentrations in the third National Health and Nutrition Examination Survey, 1988-1994. Am J Clin Nutr 2003;77:826-833. [PubMed: 12663279]

37. Merck Manual of Diagnosis and Therapy. 17. Whitehouse Station: Merck Research Laboratories; 1999.

38. Hummel M, Buchheidt D, Reiter S, Bergmann J, Hofheinz R, Hehlmann R. Successful treatment of hyperuricemia with low doses of recombinant urate oxidase in four patients with hematologic malignancy and tumor lysis syndrome. Leukemia 2003;17:2542-2544. [PubMed: 14523460] 


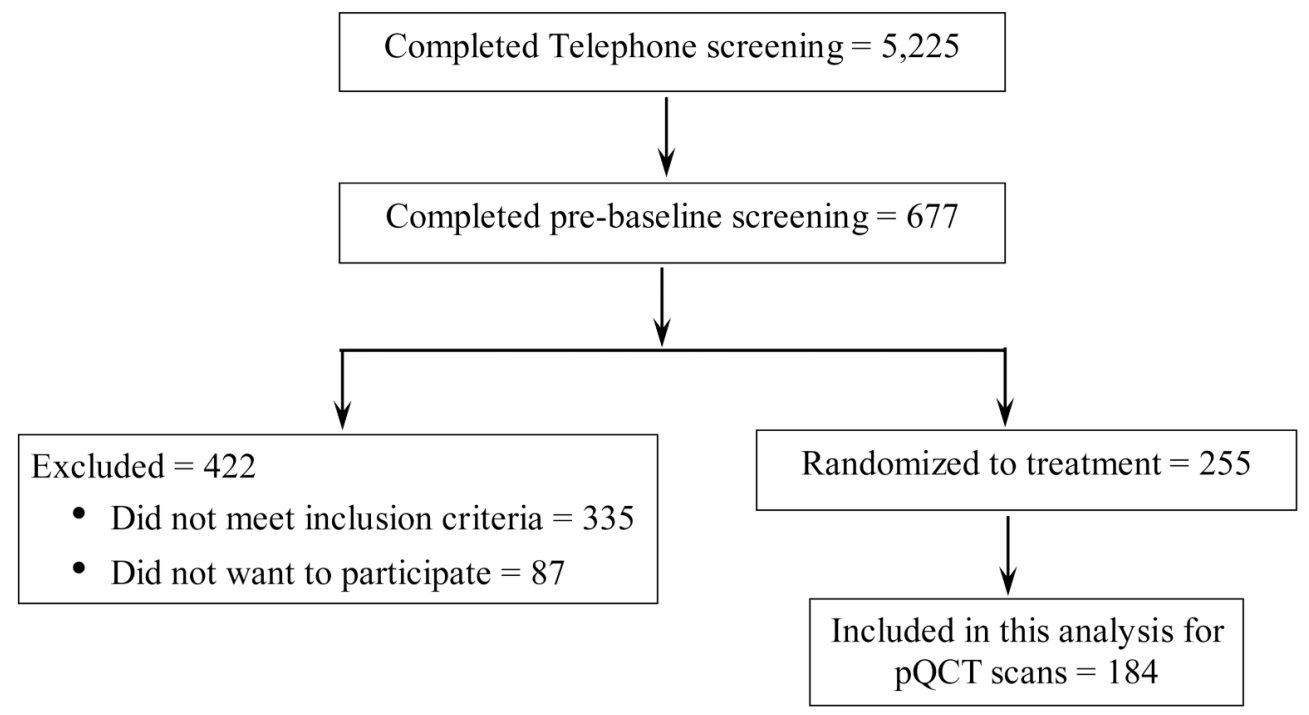

Figure 1.

Subject screening and enrollment flow chart 
Table 1

Characteristics of Subjects $(\mathrm{N}=184)$ at Baseline

\begin{tabular}{|c|c|c|c|}
\hline & Mean \pm SD & Median & Min-Max \\
\hline $\begin{array}{l}\text { Age (years) } \\
\text { Years since menopause } \\
\text { Estrogen exposure (years) }\end{array}$ & $54.2 \pm 3.1$ & $\begin{array}{l}2.8 \\
38\end{array}$ & $\begin{array}{c}0.9-10.2 \\
27-48\end{array}$ \\
\hline $\begin{array}{l}\text { Family history of cardiovascular disease } \\
\text { Family history of osteoporosis } \\
\text { Personal history of bone fracture }\end{array}$ & $\begin{array}{c}\text { Number }(\%) \\
108(58.7) \\
53(28.0) \\
71(38.6)\end{array}$ & & \\
\hline $\begin{array}{l}\text { Past hormone therapy use } \\
\\
\text { Estrogen + progestogen } \\
\text { Estrogen } \\
\text { Progestogen/progesterone }\end{array}$ & $\begin{array}{c}\text { Number }(\%) \\
79(42.9) \\
14(7.6) \\
17(9.2)\end{array}$ & 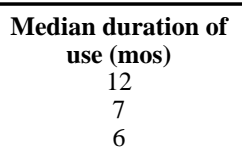 & $\begin{array}{c}\text { Min - Max (mos) } \\
0.3-120 \\
1.0-60 \\
1.0-36\end{array}$ \\
\hline $\begin{array}{l}\text { Body Size } \\
\text { Height }(\mathrm{cm}) \\
\text { Weight }(\mathrm{kg}) \\
\text { BMI }\left(\mathrm{kg} / \mathrm{m}^{2}\right)\end{array}$ & $\begin{array}{c}\text { Mean } \pm \text { SD } \\
165.0 \pm 6.1 \\
67.7 \pm 8.8 \\
24.8 \pm 2.8\end{array}$ & & \\
\hline
\end{tabular}

${ }^{a}$ Estrogen exposure (in years) $=$ Age at last menstrual cycle - Age at menarche

$b_{\text {Distrit }}$

Distributions for these variables were not normal; thus, median [min - max] values are reported 
Table 2

Baseline Bone Mineral Content (BMC) and Bone Mineral Density (BMD) Measurements

\begin{tabular}{lc}
\hline Measurement & Mean \pm SD \\
\hline Areal Bone via DXA & N=184 \\
Total proximal femur BMC $(\mathrm{g})$ & $31.37 \pm 3.57$ \\
Total proximal femur BMD $\left(\mathrm{g} / \mathrm{cm}^{2}\right)$ & $0.907 \pm 0.073$ \\
Lumbar spine BMC $(\mathrm{g})$ & $59.02 \pm 7.14$ \\
Lumbar spine BMD $\left(\mathrm{g} / \mathrm{cm}^{2}\right)$ & $0.995 \pm 0.074$ \\
Trabecular Bone via pQCT & $\mathbf{N = 1 8 4}$ \\
Distal tibia BMC $\left(\mathrm{mg} / \mathrm{mm}^{b}\right)$ & $182.33 \pm 26.33$ \\
Distal tibia BMD $\left(\mathrm{mg} / \mathrm{cm}^{3}\right)$ & $234.492 \pm 30.490$ \\
\end{tabular}

${ }^{a}$ DXA $=$ dual energy x-ray absorptiometry

${ }^{b}$ pQCT $=$ peripheral quantitative computed tomography 
Table 3

Circulating Analytes of Subjects $(\mathrm{N}=184)$ at Baseline

\begin{tabular}{|c|c|c|}
\hline Analyte $^{a}$ & Median [Min - Max] & $\begin{array}{c}\text { Normal Value or Range Reported from } \\
\text { Literature }\end{array}$ \\
\hline Serum CRP $(\mathrm{mg} / \mathrm{L})$ & $1.1[0.05-29.9]$ & $\leq 1.5^{b}$ \\
\hline Plasma total Hcy $(\mu \mathrm{mol} / \mathrm{L})$ & $7.2[4.2-17.6]$ & $6 . \overline{8} \pm 0.1^{c}$ \\
\hline Intracellular folate $(\mathrm{ng} / \mathrm{mL})(\mathrm{N}=177)^{d}$ & $541.2[249.3-2055.2]$ & $277.1 \pm 4.6^{e}$ \\
\hline Serum folate $(\mathrm{ng} / \mathrm{mL})$ & $13.1[4.2-59.4]$ & $12.9 \pm 0.2^{e}$ \\
\hline Serum vitamin $B_{12}(\mathrm{pg} / \mathrm{mL})$ & $502.6[59.7-1360.0]$ & $628.2[535.5-720.7]^{f}$ \\
\hline Blood glucose (mg/dL) & $86[57-114]$ & $<100^{g}$ \\
\hline Hemoglobin $(\mathrm{g} / \mathrm{dL})(\mathrm{N}=180)^{h}$ & $13.6[10.4-16.3]$ & $12-16^{i}$ \\
\hline Serum uric acid (mg/dL) & $4.2[1.1-7.6]$ & $3.5-7^{j}$ \\
\hline
\end{tabular}

${ }^{a}$ Distributions for these analytes were not normal; thus, median [min-max] values are reported.

${ }^{b}$ Median value reported by Bassuk et al. (10) for American women not on hormone therapy.

${ }^{c}$ Value reported is mean \pm SE from NHANES III data for women (36).

$d_{\mathrm{N}=177}$ as 3 intracellular folate samples were incorrectly processed and 4 were missing $\mathrm{CBC}$ and hence hematocrit values.

${ }^{e}$ Values reported are geometric means \pm SE from NHANES 2001-2002 data for women (6).

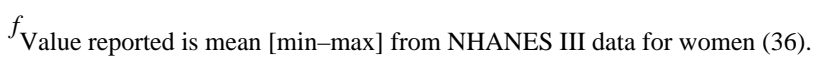

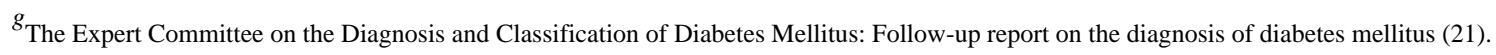

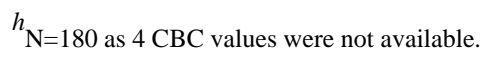

${ }^{i}$ Merck Manual of Diagnosis and Therapy (37).

$j_{\text {Hummel et al. (38). }}$ 
Table 4

Dietary Intake of Subjects $(\mathrm{N}=184)$ Based on Questionnaires

\begin{tabular}{|c|c|c|}
\hline & Median & Min - Max \\
\hline \multicolumn{3}{|c|}{ Nutrient intake from food, based on Food Frequency $a, b$} \\
\hline Riboflavin (mg/day) & 1.6 & $0.3-3.9$ \\
\hline Vitamin $\mathrm{B}_{6}(\mathrm{mg} /$ day $)$ & 1.5 & $0.4-4.6$ \\
\hline Folic acid ( $\mu \mathrm{g} /$ day $)$ & 320 & $78-1013$ \\
\hline Vitamin $\mathrm{B}_{12}(\mu \mathrm{g} /$ day $)$ & 3.3 & $0.4-10.4$ \\
\hline Calcium (mg/day) & 697 & $152-2446$ \\
\hline Supplemental calcium (mg/day) & 323 & $0-1130$ \\
\hline \multicolumn{3}{|c|}{ Lifetime calcium intake ( $\mathrm{mg} / \mathrm{day}$ ) from dairy products, based on Nutrition History $b, c$} \\
\hline Childhood (5-11 years) & 870 & $0-2964$ \\
\hline Adolescence ( $12-18$ years) & 725 & $0-4118$ \\
\hline Young adult (19-34 years) & 581 & $0-2989$ \\
\hline Midlife adult (35-49 years) & 496 & $0-2409$ \\
\hline Mature adult $(\geq 50$ years $d$ ) & 435 & $0-1886$ \\
\hline
\end{tabular}

$a_{\text {Reported from Semi-Quantitative Food Frequency Questionnaire. }}$

${ }^{b}$ Distributions for these variables were not normal; thus, median [min-max] values are reported.

${ }^{c}$ Reported from nutrition history questionnaire.

$d_{\text {Number of women who were } \geq 50 \text { years of age at baseline }=165 .}$. 
Table 5

Regression Analysis: Contributors to Trabecular Bone Mineral Content and Density

\begin{tabular}{|c|c|c|c|c|}
\hline \multicolumn{5}{|c|}{$\begin{array}{l}\text { Trabecular Bone Mineral Content at the Distal Tibia }{ }^{a, b} \\
\text { Overall Model } R^{2}=21.6 \%\left(\text { Adj } R^{2}=19.4 \%\right)[F=9.59 ; d f=(5,174)] p \leq 0.0001\end{array}$} \\
\hline Parameter & Parameter Estimate & Percentage Variance $^{c}$ & Prob $>|\mathrm{t}|^{d}$ & Variance Inflation Factor ${ }^{e}$ \\
\hline $\begin{array}{l}\text { Intercept } \\
\text { Study site } \\
\text { Weight } \\
\text { Hemoglobin } \\
\text { Serum uric acid } \\
\text { Serum glucose }\end{array}$ & $\begin{array}{c}77.0460 \\
1.8739 \\
1.0625 \\
6.7740 \\
-5.3385 \\
-0.4056\end{array}$ & $\begin{array}{c}0.001 \\
12.37 \\
5.54 \\
4.17 \\
1.48\end{array}$ & $\begin{array}{c}0.016 \\
0.62 \\
\leq 0.0001 \\
0.0006 \\
0.0027 \\
0.071\end{array}$ & $\begin{array}{l}1.23 \\
1.04 \\
1.16 \\
1.19 \\
1.21\end{array}$ \\
\hline \multicolumn{5}{|c|}{$\begin{array}{l}\text { Trabecular Bone Mineral Density at the Distal Tibia } b \text {, } \\
\text { Overall Model } \mathrm{R}^{2}=5.4 \%\left(\text { Adj } \mathrm{R}^{2}=3.8 \%\right)[\mathrm{F}=3.36 ; \mathrm{df}=(3,176)] p=0.020\end{array}$} \\
\hline Parameter & Parameter Estimate & Percentage Variance ${ }^{c}$ & $\operatorname{Prob}>|\mathbf{t}|^{d}$ & $\begin{array}{l}\text { Variance Inflation } \\
\text { Factor }^{e}\end{array}$ \\
\hline $\begin{array}{l}\text { Intercept } \\
\text { Study site } \\
\text { Hemoglobin } \\
\text { Total Hcy }\end{array}$ & $\begin{array}{c}157.1448 \\
5.1427 \\
6.5090 \\
-1.6631\end{array}$ & $\begin{array}{l}0.59 \\
4.15 \\
1.45\end{array}$ & $\begin{array}{c}\leq 0.0001 \\
0.2955 \\
0.0060 \\
0.1022\end{array}$ & $\begin{array}{l}1.10 \\
1.08 \\
1.02\end{array}$ \\
\hline \multicolumn{5}{|c|}{$\begin{array}{l}a \text { Additional variables included in the trabecular bone mineral content model: age, total Hcy, serum CRP, and total calcium (dietary plus supplemental) } \\
\text { intake. }\end{array}$} \\
\hline \multicolumn{5}{|c|}{$\begin{array}{l}{ }^{b} \mathrm{~N}=180 \text { for the trabecular bone mineral content and bone mineral density models, since } 4 \text { additional women were missing CBC and hence hemoglobin } \\
\text { values. }\end{array}$} \\
\hline \multicolumn{5}{|c|}{${ }^{c}$ Squared semi-partial Type II correlation coefficient; accounts for shared variance among variables. } \\
\hline \multicolumn{5}{|c|}{${ }^{d}$ Variables (except site) left in the model are significant at $p \leq 0.10$ level. } \\
\hline \multicolumn{5}{|c|}{$\begin{array}{l}e^{e} \text { Measures the impact of collinearity among the independent variables in a regression equation and the degree to which multicollinearity degrades the } \\
\text { precision estimate. }\end{array}$} \\
\hline
\end{tabular}

